\title{
The Need for a Comprehensive Record Keeping System in Hospitals
}

\author{
Ms Kudzayi Chiwanza ${ }^{1}$, Dr. Chipo Mutongi ${ }^{2}$, \\ ${ }^{I}$ PhD Candidate, Msc, BA, Dip-LIS,NC-LIS \\ ${ }^{2} P h D, M S c, M B A, B A, H N D-L I S$, Dip-Edu, Dip-LIS, Dip-P Magnt, Dip- Salaries Admn. \\ Zimbabwe Open University
}

\begin{abstract}
No hospital can function without records management. A comprehensive records keeping system is critical in hospitals as it encompasses all the organisational activities. It facilitates in accurate capturing of records which results in effective and efficient patient treatment. Quick records retrieval will be made possible due to comprehensive records management systems. This article gives an overview of the need of a comprehensive record keeping system as hospital records forms the backbone of effective and efficient hospital procedures.
\end{abstract}

Key terms: records, records management, Comprehensive Record Keeping System, hospital, case-notes, $x$ rays, medical records, information, hospital, records, medicine, nurse, paramedics, pharmacy.

\section{Introduction}

Records represent a particular and crucial source of information in both public and private hospitals. Records must provide a reliable, legally verifiable source of evidence of decisions and actions. A comprehensive record keeping system in hospitals should always be to build the creation and capturing of records into the business process itself, rather than require people to create records as the need arise. Yeo (1999) opines that without accurate, comprehensive up-to-date and accessible patient case-notes, medical personnel may not offer the best treatment or may in fact misdiagnose a condition, which can have serious consequences.

\section{Purpose Of The Article}

The purpose of the article is to show the necessity of an integrated hospital records management system.

\section{What Is A Record?}

Sheperd and Yeo (2003) proffer that originally record was a legal term and records were writings presented in courts of law and accepted by them as authentic testimony of completed action. Today the word record is used to mean any recorded evidence of an activity. The term 'record' according to Millar (1997), includes all the documents that institutions or individuals create or receive in the course of administrative and executive transactions. The records become the evidence of such transactions and are subsequently maintained by or on behalf of those responsible for the transactions, who keep the records for their own future use or for the use of their successors or others with a legitimate interest in the records. Penn (1989) defines a record as any information captured in reproducible form that is required for conducting business. However, the determination as to what constitutes a record is based on the context in which the information is created. According to the Guide for Managing e-records (1997), a record is recorded information produced or received in the initiation, conduct or completion of an institutional or individual activity and that comprises content, context and structure sufficient to provide evidence of the activity regardless of the form or medium. A record is also understood to be any important document that is worth keeping. It is generated or received by organizations or individuals in the conduct of their businesses. Today modern records are found in paper, digital, microforms, photographs, drawings, Braille, and so on, as long as they provide evidence of a transaction. They play a vital role in the creation, storage and flow of information and knowledge communicated in all aspects of life. Records exist because of the need to keep information of transactions carried out, and serve as evidence to identify the authoritative and reliable sources of information drawn up to accomplish work. Ngulube (2001) also defined records as documents created, received, and maintained as evidence and information by an agency, organization, or person, in pursuance of legal obligations or in the transaction of business. However, while all records convey information, not all sources of information are necessarily records; for example, published books will not be records although information selected and re-used in a new context may become a record. Records arise from actual happenings and should be snapshots of actions or events and offer pictures of something that happened. 


\section{Comprehensive Record Keeping System}

In a hospital, a comprehensive record keeping system is regarded as a set of and controls that govern a number of processes. It has to cover all the hospital processes and the whole process of records management.

\section{Types Of Hospital Records}

Most hospitals public or private create many types of medical records and some of them are patient case-notes, x-rays, specimens, patient indexes and registers, drug records, administration, educational for nursing and wards records. Case- notes are created or written when a patient comes into contact with any member of the medical staff. Notes may also be created to record contact with Nurses, Doctors, Physiotherapists, Occupational Therapists and others involved in patient care. Case- notes include patient histories, diagnostic test results and temperature, blood pressure and other charts, as well as records of operations and other forms of treatment. Yeo (1999) avers that ideally, the hospital records manager will be responsible for all records in the hospital, but in reality, but in reality such records as X-rays and pathological preparations may be maintained by technicians at the local level. All these records are created in different sections of the hospital but they must all comply with the overall system that the institution has adapted.

A record keeping system gives a set of procedures to follow when new patients visit the hospital for the first time. The patient's full names and address, referral letters and other relating documents build up to form a complete medical history of the patient and must be kept at the hospital for referral purposes. The office of the chief nurse will generate records of the type found in any office with an executive or administrative function: correspondence, reports, minutes of meetings, staff records and so on. Yeo (1999) assets that the chief nurse may be expected to keep copies of any rules and procedures issued for nursing staff or for patients which are important records, though unlikely to be bulky. He goes on to say that in the wards, records may be produced in larger quantity. Wards may maintain their own admission registers, in addition to the hospital's central record of admissions and discharges. Property and clothing books may be used to provide a record of any possessions received into custody when patients are admitted and to document their return to the patient or his or her representative on discharge or death.

\section{Why A Comprehensive Record Keeping System?}

An effective records management system must accommodate both manual and electronic transactions so that they can be useful to the hospital, its staff and clients. A comprehensive records management system manages records thorough out their life cycle from design, creation, current, semi-current and archival stages. The life cycle of a record illustrates that records are not static but go through some stages as a human being. Thus, records should be managed from conception, birth, middle age, youth, old age and death, those which will never die and some which will resurrect.

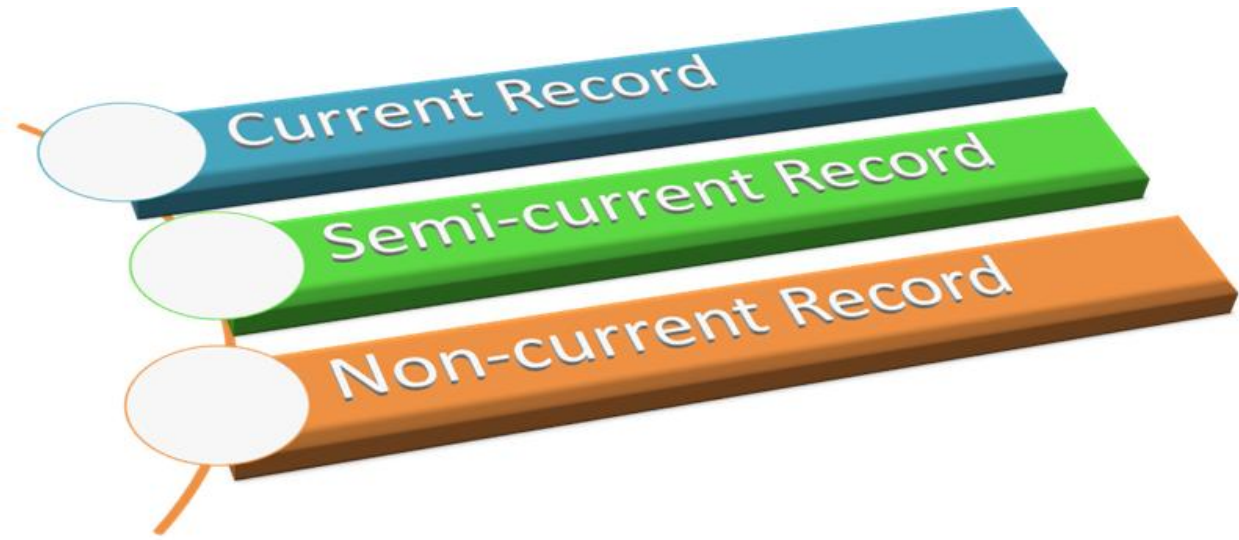

Figure 1: Records Life Cycle

The comprehensive records management system also takes note of the continuum concept. In a continuum there are no separate steps as managing records is seen as a continuous process where one element of the continuum passes seamlessly into another (Sherperd and Yeo (2003). Comprehensive records management system monitors and ensures that all patient information has been captured and foresees that the information provided is complete and accurate. Inaccurate information hinders the medical procedures and can actually result to wrong diagnoses and treatment. Records staff must make sure that all the patient information is accurately captured before letting the patient go. It is important to cross check your work for completeness before moving to the next patient. Quality records keeping can be a good reflection of the standard of care we 
give to our patients, careful, neat and accurate patient records are the hallmarks of caring and responsible health professionals. Unprofessional records leads to doubts about the quality of service.

Quick Retrieval is made possible due to a comprehensive hospital record management system. The records should me quickly made available so as to save patient's time. Proper documentation and filing of patient's medical records ensure easy retrieval and decreased patient waiting time at the hospital and ensures continuity of access. A well-managed records keeping system will be up to the task of quick provision of patient case-notes at the outpatient so that medical professional will be fast to trace diseases and give prescriptions to patients. The pharmacy must keep up to date inventory of all drugs ordered and by just using their stock cards and issue vouchers.

Properly managed hospital systems assist in accurate capturing of records. For example recording how an elderly patient had benefited from cataract operation. Harding (2006) alludes that record keeping is a dynamic and vital part of the nurse's role. Nurses are accountable to their patient, themselves, the public, their employer and supervisory body, therefore ensuring best practice by partaking in on-going record keeping education is productive for patient's safety. When records are well structured, the hospital functions are improved. Executives and supervisory sections needs reliable and compressive records information to enable them to formulate policies and make informed decisions on the basis of well organised, accurate and authentic information. If hospital records are not comprehensively managed, a patient might be given a drug which is resistant to her/him as evidenced by earlier tests which were not properly documented.

Accountability will be achieved as the audit of patient documentation is a facet of risk management and can help to promote quality as it means standards can be stressed and areas off improvement will be identified. Millar (1999) propounds that all organisations and departments that uses state funds such as the health sector must be accountable to their operations. Hospitals must account for every cent that they use whether for services or on buying medicine and assets. The foundation of accountability is based on reliable records that are safe, authentic and unique. Compressive records management system coordinates functions to archive a goal in a more professional manner. Records inform how things were treated as a result assisting health personal to predict the causes and their cure.

Electronic records management systems reduce risk of data replication as there is only one updated file, which means the file is most likely up to date and decreases risk of lost paperwork. A comprehensive electronic medical records keeping system assist better training for paramedic's review of clinical standards, better research options for the hospital care and design of future treatment options. It facilitates a backup system.

Some hospital records have underused the records system (O'Neill, 2006). There might be some missing entries. In some hospital storage of and access to records was criticised as some patient files disappeared, leading to time wastage, decreased evidence and reduced transparency. The use of electronic records management system is also being underused by some hospitals due to limited computer access. Lack of complete computerisation witnessed in some hospitals results in delays. This calls for a complete hospital records management computerisation implementation in hospitals as with only a click of a button one can access a patient's record. One of the authors of this article has this to say "I visited a certain private hospital of which $l$ witnessed full computerisation of records. There was no physical paper work done with only a click of a button, my bio data, previous visits and tests results were shown my time was not even wasted". This actually results in client satisfaction and results in continual coming back of clients.

Integrated hospital records management system promotes and confidentiality. There laws and regulations that have to be strictly followed to ensure that health records are kept confidential and can only be accessed by health professionals directly involved in your care.

\section{Recommendations}

The following are some of the recommendations that can be applied for effective and efficient hospital records management:

- All hospitals should have an integrated records management systems which promotes records accuracy and currency;

- Complete hospital records management computerisation is called for;

- Hospitals must have defined records filing system with adequate training logistics and regular monitoring and supervision to minimise issuance of multiple folders and misfiling;

- Hospital records digitisation is called for;

- Records staff to have appropriate qualifications and professionalism.

- Medical staff to also undergo records management training;

- Records management should be one of the courses of health professionals as failure to manage records impact negatively on the heath system. 


\section{Conclusion}

A comprehensive records hospital management system is called for efficient and effective medical records management. This will result in quick capturing, storing and retrieval of records to save time as time is a very crucial issue in medicine. Accountability will be necessitated as well as proper hospital procedures are maintained due to integrated records management system.

\section{References}

[1]. A Guide for managing e-records. From an archival perspective. (1997) ICA Committee on e-records.

[2]. Harding, C.M (2006) The Lourdes Hospital Enquiry: An Inquiry into peripartum Hysterectomy at Qurlady of Loudes Hospital. Drogheda: Dublin Stationary Office.

[3]. Millar, L. (1997). Principles of records and archives management. London: IRMT

[4]. Ngulube, P. (2001). Workshop on standards and ethics in records and archives management. Harare: Management Training Bureau.

[5]. O’Neill, D (2006) Leads Cross Review. Dublin: Department of Health and Children.

[6]. Penn, I. (1989). Records Management Handbook. London: Gower Publishing Limited.

[7]. Sherperd, E and Yeo, G (2003) Managing Records: Handbook of Principles and Practice. London: Facet Publishing.

\section{Bio-data}

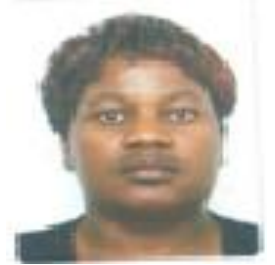

Kudzayi Chiwanza (Ms), born on $25 / 12 / 72$, is a senior lecturer, and the current Chairperson, in the Department of Information Science and Records Management at the Zimbabwe Open University, National Centre in Harare. She is the Chairperson of the Faculty of Applied Social Sciences Journal (ZOUJASS). Kudzayi is a current Dphil candidate with UNISA, holds a Master of Science in Library and Information Science (MScLIS) from the National University of Science and Technology (NUST); a Bachelor of Arts in Media Studies; a Higher National Diploma in Library and Information Science; a Diploma in Library and Information Science; and a Certificate in Library and Information Science. She has published more than 25 and presented research papers and articles in Library Management, Indigenous Knowledge, Records and Archival Preservation, Information Literacy and Quality Management. Kudzayi worked as a Librarian in different institutions in Zimbabwe, including the Zimbabwe Open University.

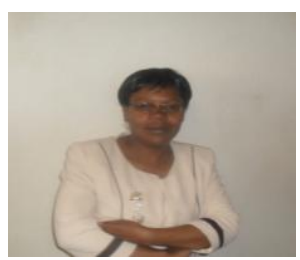

Dr. Chipo Mutongi: A part time lecturer and a $\mathrm{PhD} / \mathrm{DPhil}$ research thesis supervisor/ under study at the Zimbabwe Open University (ZOU), with more than nine years lecturing experience; Research Supervisor for all levels of education; member of the International Board of Reviewers for the International Journal of Doctoral Studies (IJDS); Journal Reviewer-Journal of Information and Knowledge Management (JIKM); published over thirty articles in International Journals; DCIZ board member for a year-Marketing and Communication, published more than ten modules with Zimbabwe Open University (ZOU); is in the process of co-authoring a book entitled: International Politics Corporation and Integration: Problems Facing Modern Day Africa; A Talent Development Officer in the City of Harare, worked as a Librarian at the City of Harare with more than eleven years experience in library, information and knowledge management; attained the highest and most prestigious degree of Doctor of Philosophy in Information and Knowledge Management (ZOU); Master of Science in Library and Information Science (NUST); the more professional degree of Master of Business Administration (ZOU); Media Studies Degree (ZOU); Higher National Diploma in Library and Information Science (Harare Polytechnic); Diploma in Library and Information Science (Bulawayo Polytechnic); Diploma in Education (UZ); Diploma in Personnel Management (IPMZ); Diploma in Salaries Administration (Stallone Consultancy); Certificate in Desk Top Publishing (CCOSA); Certificate in Web Designing (People's College); Certificate in Computer Repairs (People's College). 